\title{
The Nursing Faculty Shortage: Predictors of Job Satisfaction and Intent to Stay in Academe: A Review of the Literature
}

\section{Marcia J Derby-Davis*}

Associate Professor, Nova Southeastern University College of Nursing, South University Drive, Fort Lauderdale USA

*Corresponding author: Marcia J Derby-Davis, PhD, RN, Associate Professor, Nova Southeastern University College of Nursing, 3200 South University Drive Fort Lauderdale, FL 33328, USA, Tel: 954-618-8203; Email: mderby@nova.edu

Received date: October 3, 2014, Accepted date: December 04, 2014, Publication date:December 08, 2014

Copyright:@ 2014 Derby-Davis JM. This is an open-access article distributed under the terms of the Creative Commons Attribution License, which permits unrestricted use, distribution, and reproduction in any medium, provided the original author and source are credited.

\begin{abstract}
The United States healthcare system is faced with a critical shortage of nurses and nurse educators at the national and state levels. This shortage directly impacts the supply and demand of registered nurses (RNs) in the clinical work environments and the ability of these nurses to deliver high quality patient care. One of the challenges faced by deans and directors of schools of nursing is to identify strategies that will encourage faculty to stay in academe. Establishing a clear relationship between these variables is vital to resolving the problem of faculty shortage. A search of relevant literature across disciplines was conducted to identify the factors that contribute to the job satisfaction and /or job dissatisfaction and the intent to stay of nursing faculty who teach in BSN and graduate nursing programs. The literature review provided limited accounts of the various dimensions of the factors that predict nursing faculty's job satisfaction and / or job dissatisfaction and intent to stay in academe. None of the studies found in the literature completely focused on the subject of intent to stay of nursing faculty in academe. Therefore, this literature review will focus on the nature of faculty work, job satisfaction, demographic factors of (age, education, health, family responsibilities, teaching experience) and intent to stay.
\end{abstract}

Keywords Nursing faculty shortage; Job satisfaction; Nursing faculty workload; Motivation; Intent to stay

\section{Introduction}

The United States healthcare system is faced with a critical shortage of nurses and nurse educators at the national and state levels. This shortage directly impacts the supply and demand of registered nurses (RNs) in the clinical work environments and the ability of these nurses to deliver high quality patient care. According to the American Association of Colleges of Nursing [1] Special Survey on Vacant Faculty Positions for Academic Year 2013-2014, the vacancy rate of full-time faculty among their member schools increased to $10.8 \%$ as compared to the full-time faculty vacancy rate during the 2012-2013 academic years. The top cited recruitment barriers include, limited pool of doctoral prepared faculty (31\%), non-competitive salaries (28.4\%), and finding faculty with the right specialty mix (19.9\%). Other barriers include State budgetary constraints/ hiring freeze, expected faculty retirement, and workload.

The current faculty vacancy rate and the retirement projections of the aging faculty will directly impact the quality of nursing education as nursing schools will further limit the admission of students in proportion to the number of available, qualified faculty. Without adequate representation of faculty, nursing schools will be forced to continue to turn away qualified students who apply to their programs both at the undergraduate and graduate levels. According to the AACN [2] report approximately 79,659 qualified applicants were turned away from baccalaureate and graduate nursing programs in the United States in 2012 due to insufficient number of faculty and clinical preceptors. Other factors included insufficient clinical sites, insufficient classroom space, and budget constraints.
One of the challenges faced by deans and directors of schools of nursing is to identify strategies that will encourage the retention of current faculty members. It is important to identify the factors that contribute to the job satisfaction and/ or job dissatisfaction of nursing faculty in higher education and how these factors predict their intent to stay in academe. Establishing a clear relationship between these variables is vital to resolving the problem of faculty shortage.

A search of relevant literature across disciplines was conducted to identify the factors that contribute to the job satisfaction and /or job dissatisfaction and the intent to stay of nursing faculty who teach in BSN and graduate nursing programs. Using EBSCO HOST and ProQuest Direct search engines, the following computerized databases were used for this search: CINAHL Plus with Full Text, Cochrane Database of Systematic Reviews (CDSR), Educational Resource Information Center (ERIC), Dissertation Abstracts, and Nursing and Allied Health Collection: Comprehensive. The search was conducted using the keywords nursing and faculty shortage, nurse educators and job satisfaction, retention and recruitment and nursing faculty, nursing faculty and workload, tenure and nursing faculty, faculty rank and promotion, motivation, and intent to stay and nursing faculty. Citations were limited by language to English and by subject to explore the concepts.

The literature review provided limited accounts of the various dimensions of the factors that predict nursing faculty's job satisfaction and / or job dissatisfaction and intent to stay in academe. None of the studies found in the literature completely focused on the subject of intent to stay of nursing faculty in academe. Therefore, this literature review will focus on the nature of faculty work, job satisfaction, the demographic factors of (age, education, health, family responsibilities, teaching experience) and intent to stay. 


\section{The Nature of Faculty Work}

The academic world is faced with high level expectations. According to Boyer [3], educators in academe must excel in research, teaching, and service. Nursing faculty members are not exempt from these requirements. In fact, the American Association of Colleges of Nursing's (AACN) Position Statement on Defining Nursing Education [4] defined scholarship in nursing in terms of discovery, integration, practice, and teaching. Nurse educators are encouraged to conduct interdisciplinary research that supports evidence-based practice. In addition to research, nurse educators must keep current in clinical knowledge through professional development and the utilization of technical skills in specialty areas.

The career satisfaction and success of nursing faculty have been threatened by heavy workloads, multiple role expectations, scholarship, and service [5-7]. The multiple role expectations have a great potential to create conflict with one another, which in turn could influence the job satisfaction and/or job dissatisfaction of nursing faculty [6,7]. Findings from Balogun et al. [8] study indicated that nursing educators had significantly higher teaching workloads $(\mathrm{t}=$ $4.10, \mathrm{p}=0.001)$ than allied health educators. Despite the heavy workload of nurse educators, teaching was identified as the primary criteria used in the decision-making process for tenure among allied health and nursing educators [8]. In addition to heavy workloads, a career in nursing education is not as lucrative when compared to salaries in the clinical setting. There is a significant disparity between the national estimated annual wages for registered nurses (RN's) when compared to nurse educators. According to the United States Department of Labor Occupational Employment and Wages [9], the median national estimated wage for RN's was $\$ 65,950$ as compared to the median annual wage of $\$ 59,380$ for nurse educators.

\section{Job Satisfaction}

Job satisfaction has been identified in the literature as a variable that promotes retention in organizations. Individuals who are satisfied with their jobs have high levels of motivation and organizational commitment [10-12]. Peterson and Weisenberg [13] conducted a comparative study to investigate the job satisfaction and professional fulfillment of United States and Canadian university faculty. The sample consisted of 101 Canadian educators and 86 United States educators employed in the fields of Adult Education and Human Resource Development. The top three sources of professional fulfillment reported by the Canadian faculty were teaching (98.4\%), interactions with students $(96.9 \%)$, and working in an intellectual environment (84.1\%). The top sources of professional fulfillment for the United States faculty were: interactions with students (98.9\%), working in an intellectual environment (95.3\%), teaching (93.6\%), and satisfaction from field (89.1\%), working in a collegial environment $(84.4 \%)$, and opportunity to assume a leadership position (82.8\%). The top sources of dissatisfies for Canadian faculty were overall organizational climate $(33.3 \%)$, challenge of publishing $(31.8 \%)$, and administrative responsibilities (30.2\%). The United States faculty reported organization and administrative support (34.9\%), administrative responsibilities (34.4\%), and salary package (31.7\%) as top sources of dissatisfaction. The faculty reported that the greatest challenge to personal fulfillment was time. Additionally, the political environment of the university, bureaucracy, and red tape were also reported as challenges.
Unlike Peterson and Weisenberg's [13] study, Ambrose et al. [14] used a qualitative design study to explore faculty satisfaction. The researchers matched $(\mathrm{N}=123)$ individuals who were current or former faculty members at a medium size university. The majority of the former faculty (54\%) left the institution on their own, and $26 \%$ received tenure prior to leaving the institution. The semi-structured interviews were conducted over the telephone. The participants were asked to describe their experiences and tell their stories in their own words. Additionally, they were asked to describe any critical incidents or significant factors that affected their experience. More than half of the former faculty (54\%) rated the overall experience as positive, compared to $43 \%$ who rated the overall experience as negative. Fiftythree percent of the current faculty reported that they were satisfied with the institution and planned to stay. Non-competitive salaries were reported as a source of dissatisfaction among $16 \%$ of the current faculty and $34 \%$ of the former faculty.

While the findings from Peterson and Weisenberg [13] and Ambrose et al. [14] studies support the notion that job satisfaction plays an important role in the decision-making process of faculty members' intent to stay at the current place of employment, there remains a gap in the literature about the factors that predict nursing faculty's intent to stay in academe. Age, level of education, health, family responsibilities and teaching experience are significant variables that may impact job satisfaction and/or job dissatisfaction of nursing faculty.

\section{Demographic Factors}

\section{Age}

The United States is faced with the "graying of the nursing faculty." The average age of full-time doctoral nursing faculty in the United States has steadily increased from 49.7 years in 1993 to 54.3 years in 2004. Similarly, the age of master's prepared faculty has also increased from 46.0 years in 1993 to 49.2 years in 2004. The average age of retirement for nursing faculty continues to be 62.5 years [15]. Findings from Kowalski et al. [16] study identified the top five factors that influenced retirement decisions of the nursing faculty which included financial security $(\mathrm{n}=83,64.3 \%)$, support from significant other $(\mathrm{n}=$ $68,57.6 \%)$, job satisfaction $(\mathrm{n}=49,38 \%)$, mentally challenging activities ( $\mathrm{n}=37,28.9 \%)$, and meaningful activities $(\mathrm{n}=37,28.9 \%)$. Other factors included the retirement age of their significant other ( $77 \%$ of the participants were married), personal and family health ( $86 \%$ considered themselves to be healthy), and family support ( $\mathrm{n}=$ $25,19.4 \%)$. The nursing faculty considered 62.4 years as the optimal retirement age. While the above mentioned study addressed the factors that influenced the retirement decisions of nursing faculty, the researchers did not address level of education, family responsibilities, and teaching experience.

\section{Education}

Level of education has been identified in the literature as a variable that impact job satisfaction. Sharma and Jyoti [17] investigated the intrinsic and extrinsic factors that affected the job satisfaction of university teachers. The random sample consisted of $(\mathrm{N}=120)$ teachers who worked at the University of Jammu. Job satisfaction was measured using Smith Kendal and Hulin's 1969 Job Descriptive Index (JDI). The instrument has established reliability and validity. The results of the study revealed doctoral prepared teachers had the highest level of job satisfaction $(\mathrm{M}=3.79, \mathrm{SD}=.0593)$. The findings from this 
study reflects that there is a significant relationship between level of education and job satisfaction $(\mathrm{F}=2.404, \mathrm{p}=.05)$. Furthermore, the results of the study revealed that as the level of education increases, the level of job satisfaction also increases.

\section{Health}

Foxall et al. [6] explored the incentives that would encourage faculty to remain in the workplace beyond retirement. The sample consisted of $(\mathrm{N}=150)$ faculty members from a college of nursing in a Midwestern university. The age of the participants ranged from 28 to 67 years $(M=52.8)$. Twenty percent of the faculty stated that adequate health, intellectual stimulation, and the ability to contribute as factors that would motivate them to remain in the workforce past retirement age. The majority of the respondents $(n=102,46 \%)$ reported part-time workload responsibilities would be an attractive incentive to work beyond retirement age. Available resources such as salary, monetary bonus or grants were cited by $25 \%(n=55)$ of the respondents as incentives to remain active in the workforce. Finally, a supportive environment and feeling valued was cited by $9 \%$ of the faculty as important factors to remain active in the workforce.

\section{Family Responsibilities}

Lowenstein et al. [18] investigated the factors that predict intentions of medical school faculty to leave academic careers. The sample consisted of 532 full-time faculty members who held the academic rank of instructor. Part-time faculty members were excluded from the study. Forty-two percent of the faculty reported that they were considering leaving academic medicine within the next five years. The strongest predictor of faculty discontent was quality of life. Quality of life was reported as difficulty balancing family and career responsibilities. The findings from this study support the notion that career balance, flexible schedules, and creative scheduling are important factors to consider in the retention of current faculty and the recruitment of new faculty. While no studies were found to address this variable related to nursing faculty, it might be implied that family responsibility may also be related to nursing's faculty intent to stay in academe.

\section{Teaching Experience}

There is limited research of the relationship between teaching experience and nursing faculty's job satisfaction and intent to stay in academe Smethem (2007) conducted a qualitative study to explore the views of beginning secondary school teachers in Europe toward their work, and their intentions for career development. The sample consisted of 16 female teachers and two male teachers. The majority of new teachers identified heavy workloads, stress, collegial relationships, and student behaviors as factors that negatively impacted their teaching experience. When asked if they could redo their career choice if they would choose teaching again, only one of the 18 teachers stated that he/she would choose teaching again if he/she had to redo his/her career choice. The researcher suggested that retention of new teachers is a primary concern for school administrators; therefore, retention strategies for new teachers should begin once they are hired and continue beyond those early years.

\section{Intent to Stay}

Price and Mueller [19] defined intent to stay as the "estimated likelihood of continued membership in an organization' (p. 546).
Garbee and Killacky [20] examined the variables that predicted nursing faculty's intent to stay in nursing education. The researchers utilized both quantitative and qualitative methods to obtain the data. Findings indicated a significant moderate positive relationship between intent to stay one year $(\mathrm{r}(313)=.40, \mathrm{p}<.001)$, intent to stay five years $(\mathrm{r}(313)=.358, \mathrm{p}<.001)$, and job satisfaction. Faculty with high levels of job satisfaction rated their intent to stay for one year and five years higher than faculty with low levels of job satisfaction. The intent to stay scores of faculty who worked 40 hours per week (M= $8.24, \mathrm{SD}=2.48$ ) were significantly higher than the mean scores of faculty who worked 60 hours per week $(M=7.13, S D=2.45)$. The themes from the qualitative data analysis indicated that approximately $20 \%$ of the faculty members were satisfied with student success, flexibility, faculty colleagues, and collegial relationships, whereas time demands (29.3\%), extremes in leadership behavior (14.3\%), low salary $(13.5 \%)$, and faculty attitudes (12.9\%) were identified as themes for job dissatisfaction.

Derby-Davis [10] utilized Herzberg's Motivation-Hygiene Theory as a theoretical framework to investigate the factors that predict nursing faculty's intent to stay in academe. Herzberg [21] identified the job satisfiers as motivation factors. These factors include achievement, recognition, responsibility, advancement, work, and growth. He also identified the job dis-satisfiers as hygiene factors. The hygiene factors include company policies and administration, supervision, interpersonal relations, working conditions, job security, and salary. Derby-Davis [10] sample consisted of 120 nursing faculty teaching in baccalaureate and graduate nursing programs in Florida. A significant positive relationship was found between level of education, teaching experience, and intent to stay $(\mathrm{p}<.05)$. A non- significant relationship was found between age, health-related conditions, family responsibilities, and nursing faculty's intent to stay in academe.

The results of Derby-Davis [10] study revealed that highly educated, experienced nursing faculty reported having more intent to stay in academe. Furthermore, a significant relationship was found between the motivation-hygiene factor score and the intent to stay. The significant relationship between the motivational factors (Job satisfiers) and the hygiene factors (job dis-satisfiers) and intent to stay indicated that the nursing faculty overall were satisfied with their jobs. The results provide support that Herzberg's Motivation-Hygiene Theory is a strong predictor of nursing faculty's intent to stay in academe.

\section{Discussion of Findings}

\section{Discussion}

The nursing faculty shortage directly impacts the supply and demand of the nursing workforce. The career satisfaction and success of nursing faculty have been threatened by heavy workloads and the multiple role expectations of teaching, service, and scholarship. In lieu of the retirement predictions of the aging nursing faculty, it is imperative that nursing administrators provide supportive environments in which resources are available so that the quality of nursing education can be sustained. Additionally, workload and promotion policies must be reviewed, and the discrepancies in salaries between academia and the clinical environment must be addressed in order in improve the job satisfaction and the intent to stay of nursing faculty. 
In terms of level of education, findings from Derby-Davis [10] study support the notion that as the level of education increase, the professional identification, and the intent to stay of nursing faculty in academe will also increase. Given the fact that the doctoral degree is the preferred preparation for faculty in higher education, it is possible that monetary or financial restraints could influence decision-making process of nursing faculty to obtain higher degrees necessary to teach in academe. Although the United States government has made great strides in providing opportunities for nursing faculty to receive financial assistance through scholarships and loan repayment programs, nurse leaders must strive to keep nursing education at the forefront of the political arena so that these loans will continue to be available to assist nursing faculty relieve the financial burden of student loans. Additionally, part-time employment may be an attractive incentive to encourage current faculty to remain in academe past retirement age and mentoring should be used as a strategy to retain new faculty with limited teaching experience. Finally, it should be noted to that Herzberg Motivation Hygiene Theory is good predictor of nursing faculty job satisfaction. By improving the motivation and hygiene factors in academe, the quality of nursing education will be sustained and the retention of current faculty will be increased.

\section{References}

1. American Association of Colleges of Nursing (2013). Nursing shortage fact sheet.

2. American Association of Colleges of Nursing (2014). Special Survey on Vacant Faculty Positions for Academic Year 2013-2014.

3. Boyer, E. L. (1990). Scholarship Reconsidered. New Jersey: Carnegie Foundation.

4. American Association of Colleges of Nursing (1999). Position statement on defining nursing education.

5. Conklin MH, Desselle SP (2007) Job turnover intentions among pharmacy faculty. See comment in PubMed Commons below Am J Pharm Educ 71: 62.

6. Foxall M, Megel ME, Grigsby K, Billings JS (2009) Faculty retirement: stemming the tide. See comment in PubMed Commons below J NursEduc 48: 172-175.

7. Sourdif J (2004) Predictors of nurses' intent to stay at work in a university health center. See comment in PubMed Commons below Nurs Health Sci 6: 59-68.
8. Balogun JA, Sloan PE, Germain M (2006) Determinants of tenure in allied health and nursing education. See comment in PubMed Commons below J AdvNurs 56: 532-541.

9. United States Department of Labor Occupational Employment and Wages (2011).

10. Derby-Davis MJ (2013) Predictors of nursing faculty's job satisfaction and intent to stay in academe. See comment in PubMed Commons below J Prof Nurs 30: 19-25.

11. Gazza EA (2009) The experience of being a full-time nursing faculty member in a baccalaureate nursing education program. See comment in PubMed Commons below J Prof Nurs 25: 218-226.

12. Gerolamo AM, Roemer GF (2011) Workload and the nurse faculty shortage: implications for policy and research. See comment in PubMed Commons below Nurs Outlook 59: 259-265.

13. Peterson, S.L., Wiesenberg, F. (2004). Professional fulfillment and satisfaction of U.S. and Canadian adult education and human resource development faculty. International Journal of Lifelong Education, 159-178.

14. Ambrose S, Huston T, Norman M (2005) A qualitative method for assessing faculty satisfaction. Research in Higher Education 46(7): 803-830.

15. Berlin LE, Sechrist KR (2002) The shortage of doctorally prepared nursing faculty: a dire situation. See comment in PubMed Commons below Nurs Outlook 50: 50-56.

16. Kowalski SD, Dalley K, Weigand $\mathrm{T}$ (2006) When will faculty retire?: Factors influencing retirement decisions of nurse educators. See comment in PubMed Commons below J NursEduc 45: 349-355.

17. Sharma RD, Jyoti J (2009) Job satisfaction of university teachers: An empirical study. Journal of Services Research, 9(2), 51-69.

18. Lowenstein, S. R., Fernandez, G., and Crane, L. A. (2007). Medical school faculty discontent: Prevalence and predictors of intent to leave academic careers. BMC Medical Edition 7(37).Smethem, L. (2007). Retention and intention in teaching careers: Will the new generation stay? Teachers and Teaching: Theory and Practice, 13(5), 465-480.

19. Price, JL, Mueller CW (1986) Handbook of organizational measurement. Marshfield, MA: Pitman Publishing Inc.

20. Garbee DD, Killacky J (2008) Factors influencing intent to stay in academia for nursing faculty in the southern United States of America. See comment in PubMed Commons below Int J NursEducScholarsh 5: Article9.

21. Herzberg, F., Mausner, B., and Snyderman, B. B. (1959). The motivation to work. New York: Wiley. 